Tennis balls

\section{Fuzzy balls}

\section{B M Pluim, M Turner}

M elbourne in January-The first Grand Slam is in full swing and the city is in the last stages of preparation for the 2006 Commonwealth Games. The temperature is over $33^{\circ} \mathrm{C}$ and we are following Noakes' first law of hydration: only drink when you are thirsty. Thankfully, Noakes' second law states that drinking does not need to be limited to commercial sports drinks, and the Australian palate is permanently parched, so we don't do too badly.

The radio commentator is interviewing the Artistic Director of the Commonwealth Games Opening Ceremony and asks how large an audience is expected to witness this spectacular event. "A wide global audience, England and, of course, the other European Commonwealth countries" comes back the answer. Naming the other nine European "countries" involved in these games was obviously

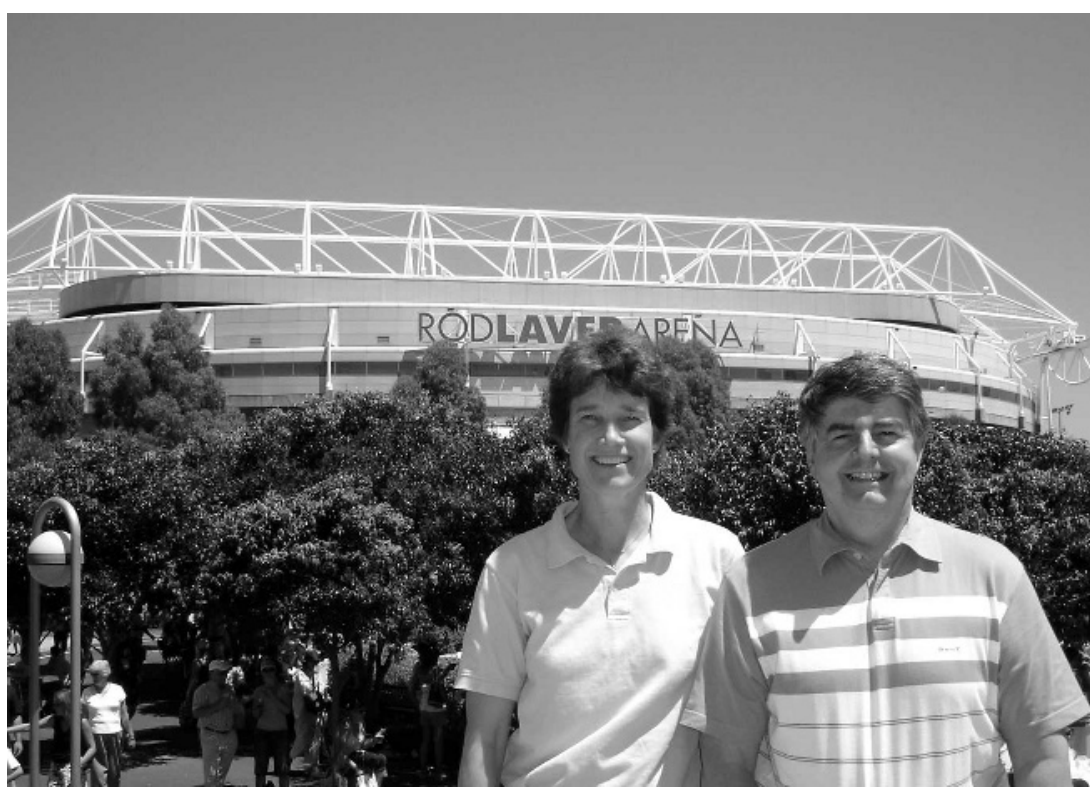

Babette Pluim and Mike Turner. Babette Pluim, MD, PhD, is Chief Medical Adviser of the Royal Netherlands Lawn Tennis Association (KNLTB) and President of the Society for Tennis Medicine and Science (STMS). She is a member of the ITF Sports Science and Medicine Commission, the ITF Wheelchair Tennis Medical Commission and the WADA Health, Medical and Research Committee Michael Turner, MD, MBBS, was formerly Chief Medical Adviser to the British Ski and Snowboard Federation and Director of Medical Services at the British Olympic Association. He is currently Chief Medical Adviser to the Lawn Tennis Association and to The Horseracing Authority (GB). down the actual BJSM editor, now that he is a full time academic at the University of Melbourne. We wanted to concentrate on our lunch at the Stokehouse, overlooking glorious St Kilda's beach; he wanted to talk about fuzzy balls.

For the non-tennis aficionado, the sight of a player collecting three or four balls from a ballboy only to discard two or three before starting to serve is often dismissed as a "neurotic ritual". In fact, this is based on good scientific data because each new ball goes through three distinct phases before it is withdrawn (after eight games).

- Phase 1: When the new ball comes out of the vacuum filled can, the pile (fuzzy hair on the outside of the tennis ball) is smoothed down on to the rubbery surface of the ball. The vacuum cans are stored at a fixed temperature of $20^{\circ} \mathrm{C}$ so that the new balls are also at this "perfect temperature" for a short period of time.

- Phase 2: When the ball is first hit by the racket (and bounces on the court surface), the pile stands up on end and the ball becomes distinctly "fuzzy".

- Phase 3: as the ball continues in use, the pile gradually gets knocked off and the ball slowly becomes smooth again. The ball also adjusts to the ambient temperature of the tennis arena.

Phase 2 balls are aerodynamically slower than balls in either phase 1 or 3 , but they will take more spin. So, you would ideally choose a smooth new ball for a first service (phase 1) and a fuzzy ball for a sliced second service. Ipso facto, Andy Roddick did not have a fuzzy ball in his hand when he served at $155 \mathrm{mph}$..

This tennis edition of the BJSM contains contributions from members of the STMS, ITF, ATP, and Sony Ericsson WTA Tour. We hope that you will enjoy this special edition and the two European Grand Slams at Roland Garros and Wimbledon!

Br J Sports Med 2006;40:378. doi: 10.1136/bjsm.2006.026039

\section{Authors' affiliations}

B M Pluim, Royal Netherlands Lawn Tennis Association (KNLTB), PO Box 1617, Amersfoort $3800 \mathrm{BP}$, the Netherlands M Turner, LTA, Queens Club, Palliser Road, London W14 9EG, UK

\section{Correspondence to: Dr Pluim, bpluim@ euronet.nl}

